\title{
Killing Patients to Save their Lives: Ethics of Emergency Preservation and Resuscitation Protocol
}

\author{
Joshua A Cuoco* \\ Department of Biomedical Sciences, New York Institute of Technology College of Osteopathic Medicine, Old Westbury, New York 11568, USA
}

Suspended animation is the temporary cessation of life without termination. Although such a protocol has been traditionally associated with science fiction, doctors at the University of Pittsburg Medical Centre Presbyterian Hospital are in the preliminary stages of investigating the feasibility in implementing a state of suspended animation to victims of penetrating trauma that are in cardiac arrest [1]. Termed emergency preservation and resuscitation (EPR), the basic technique of this procedure replaces the patient's blood with a $10^{\circ} \mathrm{C}$ saline solution in order to provide the surgeons additional time to mend the patient's wound(s) [1]. Without a heart rate or blood pressure, the patient will be considered clinically deceased during this time-a state of suspended animation. After the surgeons repair the patient's wound(s), the patient's blood will be re-administered and the patient will be "brought back to life" [1]. Although a noble venture, there are various ethical predicaments that ought to be considered in the context of this procedure.

The first ethical quandary regarding implementing EPR protocol is that it implies consent from the incapacitated patient to perform the procedure. However, in order for the patient to be considered for the protocol they must have been subject to penetrating wound(s), suffer cardiac arrest, and lost their pulse [1]. This begs the question - is patient autonomy dependent upon patient "liveliness"? Patient autonomy ought to be honored regardless of the statistical likelihood of survival. Nevertheless, the concept of implied consent of an incapacitated patient exists in every Emergency Department; however, one must determine if EPR protocol is stretching the limits of implied consent.
Similar to the ethical predicament of surpassing the boundaries of implied consent, an additional concern is the unexpected manifestations of a successful procedure. Nozari et al. demonstrated that induction of a hypothermic $\left(10^{\circ} \mathrm{C}\right)$ suspended animation state in dogs enables survival without neurologic damage after exsanguination cardiac arrest of $1 \mathrm{~h} \mathrm{[2]}$. However, no clinical data regarding this protocol exists for humans. Thus, the clinical manifestations of a successful EPR protocol in humans remain unknown. Granted the patient is successfully brought back to life, he/she will have to live with any organ damage due to the procedure. Perhaps, the patient would have preferred death instead of the resultant sequelae of the procedure?

Lastly, the question should be asked about the true intentions of this procedure. Was EPR created to save the lives of individuals suffering from penetrating trauma or to effectively preserve organs for future donation? A successful procedure (i.e., bringing the patient back to life) grants the patient more life with any organ damage due to the procedure. An unsuccessful procedure (i.e., not bringing the patient back to life) now has a deceased patient at the optimal temperature for organ preservation. Perhaps, the real question is as such-killing patients to save whose life?

\section{References}

1. Kutcher ME, Forsythe RM, Tisherman SA (2015) Emergency preservation and resuscitation for cardiac arrest from trauma. Int J Surg S1743-9191: 0127901280.

2. Nozari A, Safar P, Wu X, Stezoski WS, Henchir J, et al. (2004) Suspended animation can allow survival without brain damage after traumatic exsanguination cardiac arrest of 60 min in dogs. J Trauma 57: 1266-1275.
*Corresponding author: Joshua Aaron Cuoco, Department of Biomedical Sciences, New York Institute of Technology College of Osteopathic Medicine, Old Westbury, New York 11568, USA, Tel: 6316826781; E-mail: jcuoco@nyit.edu

Received June 18, 2016; Accepted June 21, 2016; Published June 28, 2016

Citation: Cuoco JA (2016) Killing Patients to Save their Lives: Ethics of Emergency Preservation and Resuscitation Protocol. Int $\mathrm{J}$ Neurorehabilitation 3: e125. doi:10.4172/2376-0281.1000e125

Copyright: ( 2016 Cuoco JA. This is an open-access article distributed under the terms of the Creative Commons Attribution License, which permits unrestricted use, distribution, and reproduction in any medium, provided the original author and source are credited. 